\title{
STRATEGI DAN MODEL PENGEMBANGAN WAJIB BELAJAR 12 TAHUN DI KABUPATEN BENGKALIS PROVINSI RIAU
}

\author{
Caska ${ }^{1)}$ dan Henny Indrawati ${ }^{2)}$ \\ 1) Pusat Penelitian Kependudukan/Program Studi Pendidikan Ekonomi FKIP \\ Universitas Riau; \\ 2) Program Studi Pendidikan Ekonomi FKIP Universitas Riau \\ JI. HR. Subrantas KM 12,5 Simpang Panam Pekanbaru Riau Indonesia 28293 \\ e-mail: riodirgantoro@yahoo.com
}

\begin{abstract}
ABSTRAK. Penelitian ini bertujuan untuk menganalisis: (1) strategi pengembangan wajib belajar 12 tahun; (2) posisi pengembangan wajib belajar 12 tahun; dan (3) model pengembangan wajib belajar 12 tahun di Kabupaten Bengkalis. Metode yang digunakan adalah metode survey dengan menggunakan analisis SWOT (StrengthsWeaknesses-Opportunities-Treath). Hasil penelitian menunjukkan bahwa (1) Terdapat empat strategi pengembangan model wajib belajar 12 tahun, yaitu: a) Strategi Strengths-Opportunities/SO, b) Strategi Strengths-Treath/ST, c) Strategi Weaknesses-Opportunities/WO, dan d) Strategi Weaknesses-Treath/WT; (2) Posisi pengembangan Wajib Belajar 12 tahun Kabupaten Bengkalis pada Posisi Organisasi berada pada Kuadran III (tiga); 3) Model pengembangan Wajib Belajar 12 Tahun di Kabupaten Bengkalis adalah: a) Pembangunan Unit Sekolah Baru berupa SMA/MA/SMK Reguler; b) Pelaksanaan Kegiatan Kelompok Belajar Paket C; c) Pelaksanaan Ujian Persamaan SMA; d) Pembangunan SMA Luar Biasa; dan e) Pembangunan SMA Terbuka.
\end{abstract}

Kata Kunci: wajib belajar 12 tahun, strategi pengembangan, model pengembangan

\section{THE STRATEGY AND 12 YEARS BASIC EDUCATION DEVELOPMENT MODEL IN THE REGENCY OF BENGKALIS, THE PROVINCE OF RIAU}

ABSTRACT.The objectives of the research are to analyze: (1) the development strategic of 12 years basic education; (2) the development position of 12 years basic education; and (3) the development model of 12 years basic education in Regency of Bengkalis. The method used in this research is survey method. The method for analyses is the SWOT (Strengths-Weaknesses-Opportunities-Treath). The results of the research indicate that: (1)The development strategic of 12 years basic education, are: a) Strategy of Strengths-Opportunities (S-O), b) Strategy of Strengths-Treath (S-T), c) Strategy of Weaknesses-Opportunities (W-O), and d) Strategy of Weaknesses-Treath (W-T). 2) The development position of 12 years basic education in Regency of Bengkalis is three quadrants. 3) The development 
model of 12 years basic education in The Regency of Bengkalis: a) reform a new schools unit such as SMA/MA/SMK regulery, b) implementation of package $C$ program, c) test of equel SMA, d) to create exclusive SMA, and e) to create a new open SMA.

Key Words: 12 years basic education, development strategic, development model.

\section{PENDAHULUAN}

Pembangunan yang berkaitan dengan pembinaan dan pengembangan sumberdaya manusia telah ditetapkan melalui Masterplan Pendidikan Riau 2020, di mana sektor pendidikan telah dirumuskan 6 persoalan dasar pendidikan (Pemerintah Daerah Provinsi Riau, 2007), yaitu: 1) Terdapatnya penduduk usia 7$12,13-15$, dan 16-18 tahun yang belum tertampung di bangku sekolah serta masih terbatasnya sarana dan prasarana pendidikan; 2) Rendahnya mutu pendidikan, kualitas lulusan yang belum sesuai dengan kebutuhan pasar dan lemahnya manajemen pengelolaan sekolah; 3) Belum relevannya pengembangan program studi pendidikan tinggi dengan potensi, investasi, dan pasar; 4) Masih adanya anak usia sekolah buta huruf, putus sekolah, dan drop out, 5) Rendahnya minat baca masyarakat dan terbatasnya jangkauan pelayanan perpustakaan sampai kecamatan/desa serta terbatasnya pengembangan sarana dan prasarana perpustakaan; dan 6) Terbatasnya pengalaman, pemahaman nilai budaya daerah.

Sehubungan dengan persoalan tersebut, dirumuskan 13 sasaran utama pembangunan pendidikan di Provinsi Riau. Sasaran tersebut secara terinci dijabarkan sebagai berikut, yaitu: 1) Meningkatkan pemerataan pendidikan di semua jenjang; 2) Meningkatkan fasilitas prasarana dan sarana pendidikan sekolah dan luar sekolah; 3) Mengembangkan sekolah berwawasan keunggulan di semua jenjang pendidikan; 4) Meningkatkan kualitas di semua jenjang pendidikan dan kesejahteraan tenaga pendidikan; 5) Meningkatkan manajemen pendidikan; 6) Mengembangkan kebudayaan Melayu di sekolah; 7) Mengembangkan pendidikan tinggi yang berwawasan sains dan teknologi; 8) Meningkatkan program Pendidikan Anak Usia Dini (PAUD); 9) Pengembangan semua jenis perpustakaan yang dapat menjangkau seluruh masyarakat Provinsi Riau; 10) Melakukan dan meningkatkan kerjasama di semua jenjang pendidikan di dalam dan di luar negeri; 11) Meningkatkan peranserta masyarakat dalam dunia usaha di bidang pendidikan; 12) Melestarikan peninggalan sejarah dan budaya; dan 13) Meningkatkan pengamalan beragama di semua jenjang pendidikan (Dinas Pendidikan Provinsi Riau, 2007).

Pendidikan di Kabupaten Bengkalis belum menggembirakan, hal ini dapat dilihat dari Angka Partisipasi Kasar (APK) siswa SLTP, yaitu 68,42\% dan siswa tingkat SLTA (SMU, SMK, MA), yaitu 66,74\%. Angka tersebut tergolong kategori masih rendah. Sedangkan Angka Partisipasi Murni (APM) tidak tergambarkan, dan biasanya APM lebih rendah daripada APK. Sementara, angka melanjutkan studi bagi murid SD ke SLTP dan MTs tergolong tinggi yaitu $80,7 \%$, sedangkan angka melanjutkan siswa SLTP ke SLTA adalah 69,86\% (Dinas Pendidikan Kabupaten Bengkalis, 2006). 
Mutu pendidikan dipengaruhi oleh kualifikasi yang merujuk kepada kualitas guru. Di Kabupaten Bengkalis masih ditemukan guru-guru yang berijazah SLTA, terutama pada SD dan SLTP. Di SD terdapat 31,64\% guru yang berijazah SLTA dan di SLTP terdapat $8,02 \%$ guru yang berijazah SLTA. Guru dengan kualifikasi diploma yaitu: $17,38 \%$ yang berijazah $D-1 ; 30,76 \%$ berijazah D-2; 7,58\% berijazah sarjana muda; $18,13 \%$ berijazah D-3; dan $18 \%$ yang berijazah S-1(Dinas Pendidikan Kabupaten Bengkalis, 2006).

Selain masalah tersebut, masalah pendidikan yang perlu mendapatkan perhatian adalah penduduk usia sekolah yang tidak bersekolah. Menurut data yang diperoleh, terdapat 3.450 orang usia 7-12 tahun yang tidak bersekolah, 5.092 orang usia 13-15 tahun yang tidak sekolah, dan 9.502 orang usia 16-18 tahun yang tidak bersekolah. Keseluruhan anak usia sekolah yang tidak bersekolah mencapai 18.044 orang. Di samping itu, ditemukan juga kepala keluarga yang tidak tamat SD sejumlah 26.913 orang (Kanwil BKKBN Provinsi Riau, 2006).

Sementara itu, arah kebijakan Kabupaten Bengkalis pada tahun $2006-2010$ sesuai dengan Rencana Pembangunan Jangka Menengah (RPJM) adalah menyelenggarakan Wajib Belajar 12 Tahun. Hal ini dilakukan untuk mewujudkan pemerataan pendidikan yang bermutu di Kabupaten Bengkalis dalam memenuhi hak dasar masyarakat sebagai warga negara.

Fenomena tersebut menunjukkan betapa beratnya Pemerintah Kabupaten Bengkalis untuk mensukseskan penyelenggaraan Wajib Belajar 12 Tahun yang telah dicanangkan dalam RPJM tahun 2006-2010. Namun demikian kemauan politik tersebut perlu diapresiasi dan didukung semua elemen masyarakat di Kabupaten Bengkalis agar dapat diwujudkan program Wajib Belajar 12 Tahun tersebut. Di samping itu, suasana otonomi daerah yang memberikan kewenangan yang besar kepada Pemerintah Kabupaten merupakan modal dasar suksesnya suatu program yang telah dicanangkan.

Pemberlakuan UU Nomor 22 tentang Pemerintah Daerah dan UU Nomor 25 tentang Perimbangan Keuangan Pusat dan Daerah, secara hakiki memberikan angin segar kepada daerah untuk mengatur rumah tangganya sendiri. Pemerintah pusat telah memberikan sebagian besar wewenang yang selama ini didominasi pusat dialihkan kepada pemerintah daerah. Artinya kewenangan pemerintah pusat yang bersifat sentralisitik diserahkan kepada kabupaten/kota atau desentralisasi termasuk penyerahan kewenangan sektor pendidikan. Pemerintah kabupaten/kota sudah diberikan kesempatan oleh pemerintah pusat untuk mengatur mekanisme pendidikan di daerah, sehingga apapun yang dilakukan oleh pemerintah kabupaten dan kota, akan menjadi bagian yang tidak terpisahkan dari sistem pendidikan nasional.

Pemerintah kabupaten dan kota diberikan kesempatan untuk menyusun rencana strategis upaya peningkatan mutu, pemerataan, dan pemberdayaan sumberdaya. Selanjutnya, di samping tetap mengacu kepada kurikulum nasional, pemerintah pusat memberikan kesempatan kepada daerah untuk menyusun 
kurikulum daerah. Kurikulum disusun berdasarkan potensi dan kebutuhan daerah. Kebijakan pemerintah pusat sudah dilimpahkan kepada kabupaten/kota, sekarang bagaimana peluang ini dimanfaatkan secara optimal oleh daerah.

Berdasarkan latar belakang yang telah diuraikan maka permasalahan dalam penelitian ini adalah: (1) Bagaimana strategi pengembangan model wajar 12 tahun di Kabupaten Bengkalis? (2) Bagaimana posisi pengembangan wajar 12 tahun di kabupaten Bengkalis bila dianalisis dengan menggunakan matriks evaluasi faktor eksternal dan internal? dan (3) Bagaimana model pengembangan wajar 12 tahun yang cocok di Kabupaten Bengkalis?

Penelitian in bertujuan: (1) Untuk mengetahui strategi pengembangan model wajar 12 tahun di Kabupaten Bengkalis. (2) Untuk mengetahui posisi pengembangan wajar 12 tahun di kabupaten Bengkalis bila dianalisis dengan menggunakan matriks evaluasi faktor eksternal dan internal. dan (3) Untuk mengetahui model pengembangan wajar 12 tahun yang cocok di Kabupaten Bengkalis.

Setelah penelitian ini dilakukan, diharapkan informasi yang diperoleh dapat digunakan sebagai masukan bagi pemerintah Kabupaten Bengkalis untuk pengambilan keputusan dan kebijakan pengembangan pendidikan wajar 12 tahun. Secara spesifik keluaran yang dihasilkan adalah: (1) Bagi pemerintah daerah dapat melahirkan kebijakan dalam mensosialisasikan pengembangan model wajar 12 tahun sehingga program ini dapat diterima oleh masyarakat; (2) Ditemukannya model pengembangan wajar 12 tahun di Kabupaten Bengkalis; (3) Dapat menentukan model prioritas pengembangan wajar 12 tahun di Kabupaten Bengkalis.

\section{METODE PENELITIAN}

Penelitian ini dilaksanakan di seluruh kecamatan (13 kecamatan) Kabupaten Bengkalis dengan menggunakan metode survey. Selain itu, dilakukan pula pengumpulan data dengan metode Rapid Rural Appraisal (RRA), yaitu suatu pendekatan partisipatif untuk mendapatkan data/informasi dan penilaian (assesment) secara umum di lapangan dalam waktu yang relatif pendek dan pengumpulan data sekunder dari Kantor Camat dan UPTD Dinas Pendidikan dan Olah Raga Kecamatan.Pegumpulan data primer dilakukan terhadap 13 orang Camat, 13 orang Kepala UPTD Dikspora Kecamatan, 40 orang Kepala Sekolah, 200 orang Guru, 200 orang Siswa, dan 200 Orang Tua Siswa.

Dalam penelitian ini digunakan teknik pengukuran indikator seperti yang tercantum dalam Tabel 1, dan alur penelitian seperti disajikan pada Gambar 1. Data dianalisis dengan menggunakan menggunakan metode analisis SWOT. 
Tabel 1. Teknik Pengukuran Indikator

\begin{tabular}{llll}
\hline No & Indikator & & \multicolumn{1}{c}{ Teknik Pengukuran (Unit) } \\
\hline 1 & Jumlah & - & Banyaknya gedung sekolah yang tersebar di setiap \\
& sekolah & & kecamatan, pendistribusian pada masing-masing kecamatan \\
& untuk setiap jenjang pendidikan.
\end{tabular}




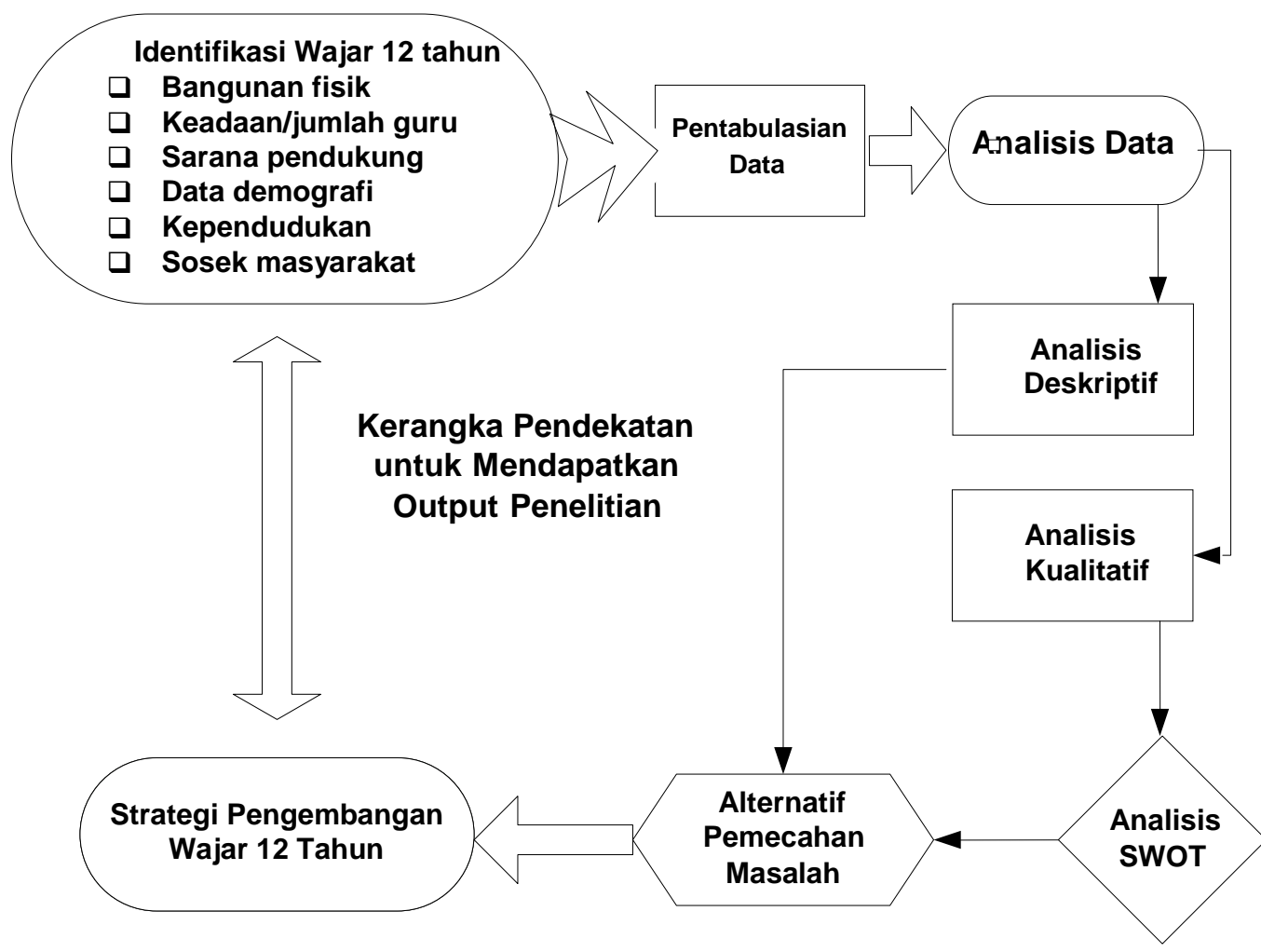

Gambar 1. Kerangka Pemikiran Pengembangan Wajar 12 Tahun

HASIL DAN PEMBAHASAN

Analisis Matriks SWOT, Matriks Evaluasi Faktor Eksternal (EFE) dan Matriks Evaluasi Faktor Internal (EFI)

Metode yang sering digunakan untuk merumuskan alternatif strategis untuk menyusun kebijakan dan program adalah Matriks SWOT (disajikan pada Tabel 2). Matriks ini dapat menggambarkan secara jelas bagaimana peluang dan tantangan eksternal yang dihadapi dapat disesuaikan dengan kekuatan dan kelemahan yang dimilikinya. Matriks ini dapat menghasilkan empat set kemungkinan alternatif strategis, yaitu: 1) Strategi kekuatan dan kesempatan (S-O); 2). Strategi kekuatan dan tantangan (S-T); 3). Strategi kelemahan dan kesempatan (W-O); dan 4) Strategi kelemahan dan tantangan ( $\mathrm{W}-\mathrm{T})$. 
Tabel 2. Matriks SWOT Strategi Pengembangan Model Wajar 12 Tahun

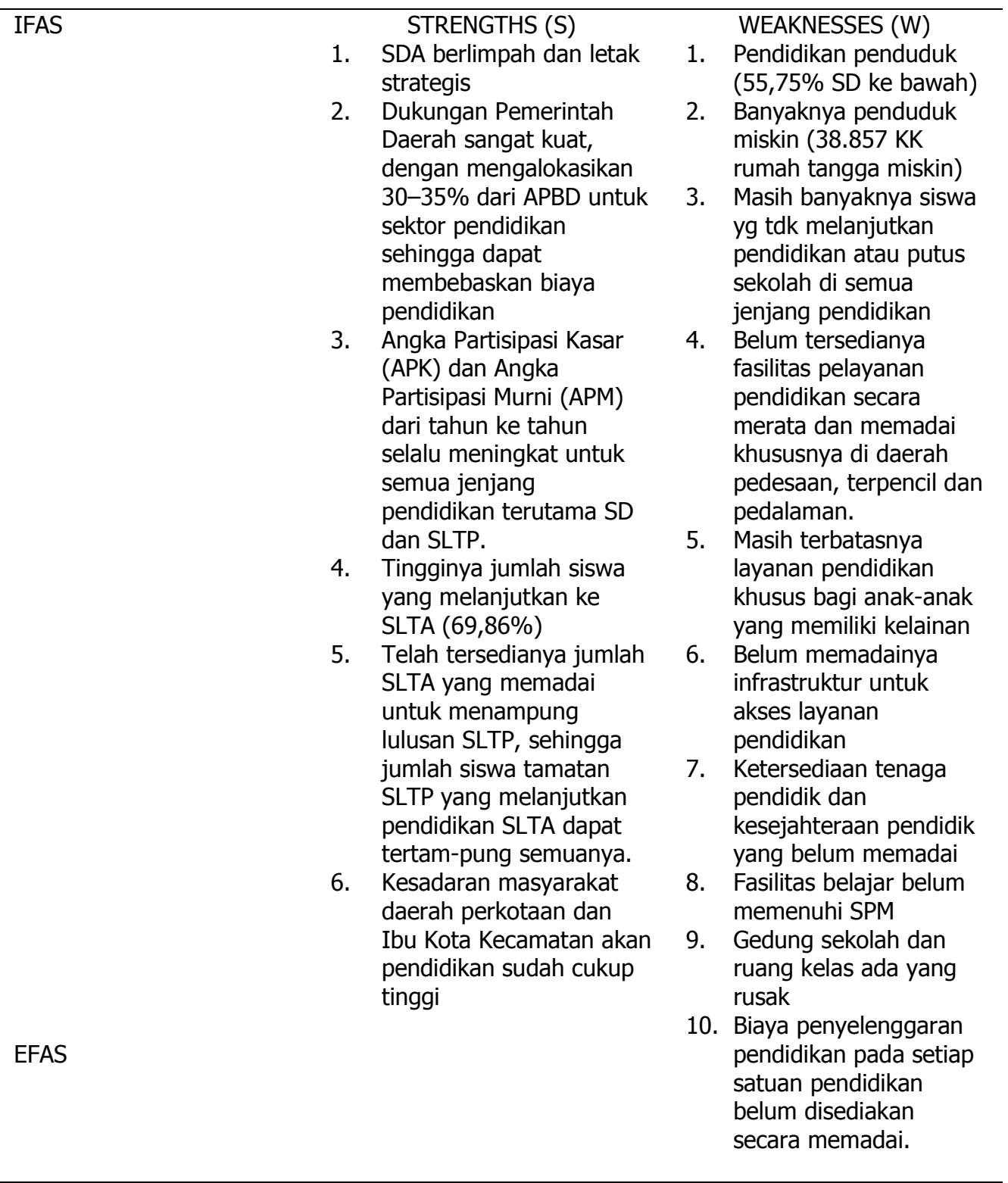




\begin{tabular}{|c|c|c|c|}
\hline \multicolumn{4}{|c|}{ OPPORTUNITIES (O) } \\
\hline \multirow[t]{6}{*}{1.} & Adanya UU yang & STRATEGI S-O & STRATEGI W-O \\
\hline & mengatur & - $\quad$ Menyusun database & Memberikan bantuan \\
\hline & perimbangan & pendidikan dan Rencana & biaya pendidikan kepada \\
\hline & keuangan antara & Strategis Pendi-dikan & masyarakat miskin \\
\hline & Pemerintah Pusat & $2007-2020\left(S_{1,2,3} ; O_{1,2,4}\right)$ & $\left(\mathrm{W}_{1,2,3} ; \mathrm{O}_{1}\right)$ \\
\hline & $\begin{array}{l}\text { dengan Pemerintah } \\
\text { Daerah, terutama } \\
\text { tentang bagi hasil SDA }\end{array}$ & $\begin{array}{l}\text { - } \quad \text { Membangun unit sekolah } \\
\text { baru dan atau menambah } \\
\text { unit lokal sesuai }\end{array}$ & $\begin{array}{l}\text { - } \quad \text { Meningkatkan partisipasi } \\
\text { masyarakat dalam } \\
\text { menyekolahkan }\end{array}$ \\
\hline \multirow[t]{2}{*}{2} & Kebijakan otonomi & kebutuhan $\left(\mathrm{S}_{2,4} ; \mathrm{O}_{3}\right)$ & anaknya. $\left(\mathrm{W}_{3}, \mathrm{O}_{4}\right)$ \\
\hline & $\begin{array}{l}\text { daerah dan } \\
\text { desentralisasi } \\
\text { pendidikan }\end{array}$ & $\begin{array}{l}\text { - } \quad \text { Menyelenggarakan } \\
\text { pendidikan yang relevan } \\
\text { dan bermutu sesuai }\end{array}$ & $\begin{array}{l}\text { - } \quad \text { Menyediakan fasilitas } \\
\text { pelayanan pendidikan } \\
\text { serta fasilitas }\end{array}$ \\
\hline \multirow[t]{2}{*}{3.} & Terjadinya percepatan & dengan tuntutan & pendukung \\
\hline & $\begin{array}{l}\text { pertumbuhan ekonomi } \\
\text { daerah sebagai akibat } \\
\text { dari meningkatnya } \\
\text { kualitas SDM }\end{array}$ & $\begin{array}{ll}\text { - } & \text { globalisasi }\left(\mathrm{S}_{4,5,6 ;} ; \mathrm{O}_{2,4}\right) \\
\text { Meningkatkan relevansi } \\
\text { daya saing pendidikan } \\
\left(\mathrm{S}_{2,6} ; \mathrm{O}_{4}\right)\end{array}$ & $\begin{array}{l}\text { (infrastruktur) secara } \\
\text { merata dan memadai } \\
\text { untuk daerah pedesaan, } \\
\text { terpencil dan }\end{array}$ \\
\hline & $\begin{array}{l}\text { Terjadinya pergeseran } \\
\text { masyarakat dari }\end{array}$ & & $\begin{array}{l}\text { pedalaman, serta untuk } \\
\text { anak yang memiliki }\end{array}$ \\
\hline & struktur tradisional ke & & kelainan. $\left(\mathrm{W}_{4,5} ; \mathrm{O}_{2,3}\right)$ \\
\hline & sektor jasa dan & & - $\quad$ Mengangkat guru baru \\
\hline & $\begin{array}{l}\text { industri, akan } \\
\text { mempenqaruhi }\end{array}$ & & \\
\hline & struktur ketenaga- & & meningkatkan \\
\hline & $\begin{array}{l}\text { kerjaan dan kesem- } \\
\text { patan kerja }\end{array}$ & & $\begin{array}{l}\text { kesejahteraannya } \\
\left(\mathrm{W}_{7 ;} \mathrm{O}_{1,2}\right)\end{array}$ \\
\hline \multirow[t]{5}{*}{5} & Terjadinya & & Melengkapi fasilitas \\
\hline & peningkatan Indeks & & belajar sesuai dengan \\
\hline & Pembangunan & & Standar Pelayanan \\
\hline & Manusia (Human & & Minimal. $\left(\mathrm{W}_{8,9} ; \mathrm{O}_{1}\right)$ \\
\hline & Development Index) & & \\
\hline \multicolumn{2}{|c|}{ TREATHS (T) } & STRATEGI S-T & STRATEGI W-T \\
\hline \multicolumn{2}{|c|}{$\begin{array}{l}\text { 1. Dukungan dan } \\
\text { kesadaran masyarakat } \\
\text { pedesaan dan suku } \\
\text { marginal terhadap } \\
\text { pendidikan masih } \\
\text { rendah }\end{array}$} & $\begin{array}{ll}\text { - } & \text { Sosialisasi Wajib Belajar } \\
\text { pada semua lapisan } \\
\text { masyarakat }\left(\mathrm{S}_{2,3,4,5} \mathrm{O}_{1}\right) \\
\text { - } \quad \text { Membuat Perda tentang } \\
\text { Penyelenggaraan Wajar } \\
12 \text { Tahun. }\left(\mathrm{S}_{3,4,5,6 ;} \mathrm{O}_{2}\right)\end{array}$ & 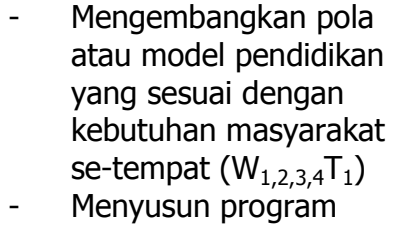 \\
\hline & Legalisasi dari DPRD & - $\quad$ Meningkatkan alokasi & pendidikan jangka \\
\hline & $\begin{array}{l}\text { Kabupaten Bengkalis } \\
\text { berupa Perda Wajar } \\
12 \text { Tahun }\end{array}$ & $\begin{array}{l}\text { anggaran untuk sektor } \\
\text { pendidikan. }\left(\mathrm{S}_{2} ; \mathrm{O}_{3}\right)\end{array}$ & $\begin{array}{l}\text { pendek, menengah, dan } \\
\text { panjang berdasarkan } \\
\text { kebutuhan dan skala }\end{array}$ \\
\hline \multirow[t]{2}{*}{3.} & Pembiayaan untuk & & priotitas \\
\hline & $\begin{array}{l}\text { sektor pendidikan } \\
\text { semakin tinggi }\end{array}$ & & $\left(\mathrm{W}_{\left.7,8,9,10 ; T_{2,3}\right)}\right.$ \\
\hline
\end{tabular}

Sumber: Hasil pengolahan data tahun 2008 
Hasil identifikasi faktor-faktor kunci eksternal yang merupakan peluang dan tantangan, pembobotan dan rating dimasukkan dalam tabel Matriks Evaluasi Faktor Eksternal (EFE) dan Matriks Evaluasi Faktor Internal (EFI) untuk diberi skor. Pemberian peringkat dan penyusunan tabel EFE dan EFI ini mengacu kepada pendekatan yang digunakan J. David Hunger \& Thomas L. Wheelen (2007). Hasil skoring (bobot dikalikan dengan peringkat/rating) baik pada tabel EFE dan tabel EFI dijumlah untuk menentukan apakah peluang lebih besar daripada tantangan atau sebaliknya serta apakah kekuatan lebih besar dari pada kelemahan atau sebaliknya. Karena jumlah bobot $=1$ maka hasil penjumlahan skor (bobot $\mathrm{x}$ peringkat) akan berada pada kisaran 1 dan 2 atau rata-rata 1,00.

Hasil analisis pada tabel Matriks Evaluasi Faktor Eksternal dan Matriks Evaluasi Faktor Internal dipetakan pada Matriks Posisi Organisasi dengan cara:

a) Sumbu horizontal ( $\mathrm{x}$ ) menunjukkan kekuatan dan kelemahan, sedangkan sumbu vertikal (y) menunjukkan peluang dan tantangan.

b) Posisi organisasi ditentukan pada diagram dengan analisis sebagai berikut:

- Jika peluang lebih besar daripada tantangan maka nilai $y>0$ dan sebaliknya tantangan lebih besar dari pada peluang maka nilai $y<0$.

- Jika kekuatan lebih besar daripada kelemahan maka nilai $x>0$ dan sebaliknya kelemahan lebih besar dari pada kekuatan maka nilai $x<0$.

Tabel 3. Matriks Evaluasi Faktor Eksternal

\begin{tabular}{lccc}
\multicolumn{1}{c}{ Faktor-faktor Kunci Eksternal } & Bobot & Rating & Skor \\
\hline \hline PELUANG/OPPORTUNITIES (O) & & & \\
\hline $\begin{array}{l}\text { 1. Adanya UU yang mengatur perimbangan } \\
\text { keuangan antar Pemerintah Pusat dengan } \\
\text { Pemerintah Daerah, terutama tentang bagi hasil }\end{array}$ & 0,14 & 2 & 0,28 \\
$\begin{array}{l}\text { SDA } \\
\text { 2. Kebijakan otonomi daerah dan desentralisasi } \\
\text { pendidikan }\end{array}$ & 0,09 & 2 & 0,18 \\
3. $\begin{array}{l}\text { Terjadinya percepatan pertumbuhan ekonomi } \\
\text { daerah sebagai akibat dari meningkatnya kualitas } \\
\text { SDM }\end{array}$ & 0,06 & 1 & 0,06 \\
4. $\begin{array}{l}\text { Terjadinya pergeseran masyarakat dari struktur } \\
\text { tradisional ke sektor jasa dan industri, akan } \\
\text { mempengaruhi struktur ketenagakerjaan dan } \\
\text { kesempatan kerja }\end{array}$ & 0,22 & 2 & 0,44 \\
5erjadinya peningkatan Indeks Pembangunan \\
$\begin{array}{l}\text { Manusia (Human Development Index) } \\
\text { Total Skor Peluang }\end{array}$ & 0,06 & 1 & 0,06 \\
\hline \hline
\end{tabular}




\begin{tabular}{|c|c|c|c|}
\hline \multicolumn{4}{|l|}{ TANTANGAN/THREATS (T) } \\
\hline $\begin{array}{l}\text { 1. Dukungan dan kesadaran masyarakat pedesaan } \\
\text { dan suku marginal terhadap pendidikan masih } \\
\text { rendah }\end{array}$ & 0,12 & 2 & 0,24 \\
\hline $\begin{array}{l}\text { 2. Legalisasi dari DPRD Kabupaten Bengkalis berupa } \\
\text { Perda Wajar } 12 \text { Tahun }\end{array}$ & 0,06 & 1 & 0,06 \\
\hline $\begin{array}{l}\text { 3. Pembiayaan untuk sektor pendidikan semakin } \\
\text { tinggi }\end{array}$ & 0,25 & 2 & 0,50 \\
\hline Total Skor Tantangan & & & 0,80 \\
\hline Selisih Skor Peluang dengan Skor Tantangan & & & 0,22 \\
\hline
\end{tabular}

Sumber: Hasil pengolahan data tahun 2008

Tabel 3. Matriks Evaluasi Faktor Internal

\begin{tabular}{|c|c|c|c|}
\hline Faktor-faktor Kunci Internal & Bobot & Rating & Skor \\
\hline \multicolumn{4}{|l|}{ KEKUATAN/STRENGTHS (S) } \\
\hline 1. SDA berlimpah dan letak strategis & 0,04 & 1 & 0,04 \\
\hline $\begin{array}{l}\text { 2. Angka Partisipasi Kasar (APK) dan Angka } \\
\text { Partisipasi Murni dari tahun ke tahun selalu } \\
\text { meningkat untuk semua jenjang pendidikan } \\
\text { terutama SD dan SLTP. }\end{array}$ & 0,10 & 2 & 0,20 \\
\hline $\begin{array}{l}\text { 3. Tingginya jumlah siswa yang melanjutkan ke } \\
\text { SLTA }(69,86 \%)\end{array}$ & 0,10 & 2 & 0,20 \\
\hline $\begin{array}{l}\text { 4. Telah tersedianya jumlah SLTA yang memadai } \\
\text { untuk menampung lulusan SLTP, sehingga jumlah } \\
\text { siswa tamatan SLTP yang melanjutkan } \\
\text { pendidikan SLTA dapat tertampung semuanya. }\end{array}$ & 0,10 & 2 & 0,20 \\
\hline $\begin{array}{l}\text { 5. Dukungan Pemerintah Daerah sangat kuat, } \\
\text { dengan mengalokasikan } 30-35 \% \text { dari APBD } \\
\text { untuk sektor pendidikan sehingga dapat } \\
\text { membebaskan biaya pendidikan }\end{array}$ & 0,04 & 1 & 0,04 \\
\hline Total Skor Kekuatan & & & 0,68 \\
\hline
\end{tabular}




\begin{tabular}{|c|c|c|c|}
\hline KELEMAHAN/WEAKNESSES (W) & & & \\
\hline 1. Pendidikan penduduk (55,75\% SD ke bawah) & 0,10 & 2 & 0,20 \\
\hline $\begin{array}{l}\text { 2. Banyaknya penduduk miskin (38.857 KK rumah } \\
\text { tangga miskin) }\end{array}$ & 0,10 & 2 & 0,20 \\
\hline $\begin{array}{l}\text { 3. Masih banyaknya siswa yg tdk melanjutkan } \\
\text { pendidikan atau putus sekolah di semua jenjang } \\
\text { pendidikan }\end{array}$ & 0,06 & 1 & 0,06 \\
\hline $\begin{array}{l}\text { 4. Belum tersedianya fasilitas pelayanan pendidikan } \\
\text { secara merata dan memadai khususnya di } \\
\text { daerah pedesaan, terpencil dan pedalaman. }\end{array}$ & 0,10 & 2 & 0,20 \\
\hline $\begin{array}{l}\text { 5. Masih terbatasnya layanan pendidikan khusus } \\
\text { bagi anak-anak yang memiliki kelainan }\end{array}$ & 0,06 & 1 & 0,06 \\
\hline $\begin{array}{l}\text { 6. Belum memadainya infrastruktur untuk akses } \\
\text { layanan pendidikan }\end{array}$ & 0,08 & 2 & 0,16 \\
\hline $\begin{array}{l}\text { 7. Ketersediaan tenaga pendidik dan kesejahteraan } \\
\text { pendidik yang belum memadai }\end{array}$ & 0,04 & 1 & 0,04 \\
\hline 8. Gedung sekolah dan ruang kelas & 0,04 & 1 & 0,04 \\
\hline $\begin{array}{l}\text { 9. Biaya penyelenggaran pendidikan pada setiap } \\
\text { satuan pendidikan belum disediakan secara } \\
\text { memadai. }\end{array}$ & 0,04 & 1 & 0,04 \\
\hline Total Skor Kelemahan & & & 1,00 \\
\hline Selisih Skor Kekuatan dg Skor Kelemahan & & & $-0,32$ \\
\hline
\end{tabular}

Sumber: Hasil pengolahan data tahun 2008

Dari hasil perhitungan dengan menggunakan Matriks EFE dan EFI diketahui bahwa:

1. Pada tabel EFE diperoleh penjumlahan skoring faktor-faktor kunci yang merupakan peluang ternyata lebih besar dari pada penjumlahan skoring faktorfaktor kunci tantangan yaitu 1,02>0,22. Hal ini berarti peluang untuk menyelenggarakan wajib belajar 12 tahun di Kabupaten Bengkalis lebih besar dibandingkan dengan tantangan yang dihadapi.

2. Sedangkan pada tabel EFI diperoleh penjumlahan skoring faktor-faktor kunci yang merupakan kekuatan ternyata lebih kecil dari pada penjumlahan skoring faktor-faktor kunci kelemahan yaitu 0,68<1,00. Hal ini berarti apabila Kabupaten Bengkalis akan menyelenggarakan wajib belajar 12 tahun, maka Pemerintah Kabupaten Bengkalis hendaknya lebih memfokuskan strateginya pada kegiatankegiatan yang meminimalkan kendala-kendala internal dan tidak pada hal-hal yang bersifat ekspansif. 
Posisi Kabupaten Bengkalis bila digambarkan dengan Diagram Posisi Organisasi berada pada Kuadran III (gambar 2), dengan karakteristik:

- Organisasi menghadapi peluang yang besar tetapi sumberdayanya lemah.

- Karena itu tidak dapat memanfaatkan peluang tersebut secara optimal, kecuali dapat meminimalkan kendala-kendala yang dihadapi.

- Fokus strategi organisasi pada posisi ini ialah mengatasi kelemahan-kelemahan atau meminimalkan kendala-kendala internal.

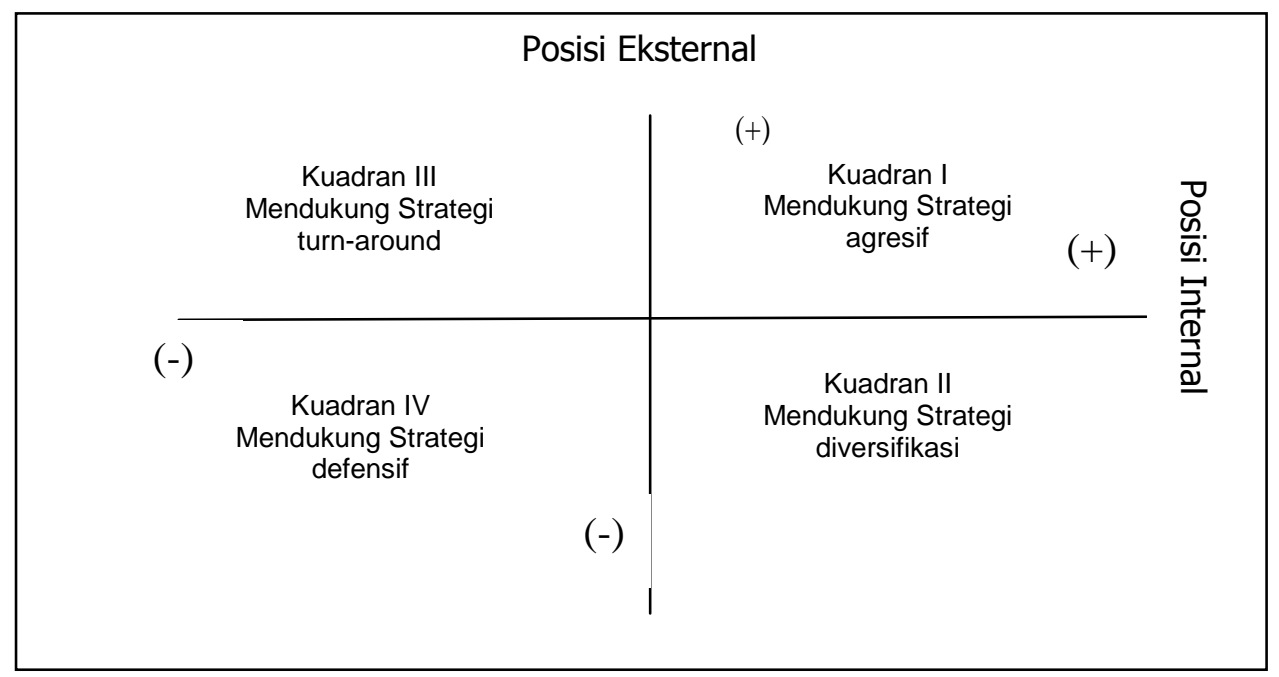

Gambar 2. Diagram Posisi Organisasi

Dengan posisi organisasi pada kuadran III ini maka Pemerintah Daerah Kabupaten Bengkalis perlu melakukan: (1) gerakan terpadu program wajib belajar 12 Tahun dengan partisipasi semua kekuatan masyarakat, seperti orang tua, tokoh masyarakat, lembaga swadaya masyarakat, dunia industri, dan usaha, sehingga pelaksanaan program ini betul-betul merupakan gerakan sosial (community-based education); (2) meningkatkan dan memperkuat program-program esensial yang telah ada untuk meningkatkan jumlah siswa masuk sekolah (enrollment); (3) Sementara itu, program-program kegiatan yang kurang esensial agar dikaji ulang dan memobilisasi sumberdaya yang mendukungnya untuk mempertahankan dan meningkatkan program wajar 12 tahun; (4) memberikan peluang yang lebih besar kepada sekolah-sekolah swasta dan lembaga pendidikan yang berbasis masyarakat untuk lebih berpartisipasi dalam pelaksanaan pendidikan menengah; (5) mengupayakan untuk menangani secara lebih efektif target-target masyarakat yang tidak terjangkau (miskin, terpencil, terisolasi) melalui pendekatan dan program pendidikan alternatif, untuk meningkatkan persamaan akses pendidikan menengah; 
dan (6) Pelaksanaan wajib belajar 12 tahun ditangani secara lokal dengan membentuk Tim Terpadu, serta memperhatikan setiap potensi dan tantangan yang ada.

Mencermati hasil pengolahan data yang disajikan maka Strategi pengembangan model wajib belajar 12 tahun, yaitu:

Strategi S-O; Strategi ini dibuat berdasarkan jalan pikiran organisasi, yaitu dengan memanfaatkan seluruh kekuatan untuk merebut dan memanfaatkan peluang sebesar-besarnya, antara lain:

- Menyusun database pendidikan dan Rencana Strategis Pendidikan 2007-2020.

- Membangun unit sekolah baru dan atau menambah unit lokal sesuai kebutuhan.

- Menyelenggarakan pendidikan yg relevan dan bermutu sesuai dengan tuntutan globalisasi.

- $\quad$ Meningkatkan relevansi daya saing pendidikan.

Strategi $S$-T; Strategi ini menggunakan kekuatan yang dimiliki organisasi untuk mengatasi tantangan, antara lain:

- $\quad$ Sosialisasi Wajib Belajar pada semua lapisan masyarakat.

- $\quad$ Membuat Peraturan Daerah tentang Penyelenggaraan Wajar 12 Tahun.

- $\quad$ Meningkatkan alokasi anggaran untuk sektor pendidikan.

Strategi $W$-O; Strategi ini diterapkan berdasarkan pemanfaatan peluang yang ada dengan cara meminimalkan kelemahan yang ada, yaitu:

- Memberikan bantuan biaya pendidikan kepada masyarakat miskin.

- $\quad$ Meningkatkan partisipasi masyarakat dalam menyekolahkan anaknya.

- Menyediakan fasilitas pelayanan pendidikan serta fasilitas pendukung (infrastruktur) secara merata dan memadai untuk daerah pedesaan, terpencil dan pedalaman, serta untuk anak yang memiliki kelainan.

- Mengangkat guru baru sesuai dengan kualifikasi dan kebutuhan serta meningkatkan kesejahteraanya.

- $\quad$ Melengkapi fasilitas belajar sesuai dengan Standar Pelayanan Minimal.

Strategi $W$-T; Strategi ini didasarkan pada kegiatan yang bersifat defensif dan berusaha meminimalkan kelemahan yang ada serta menghindari tantangan.

- Mengembangkan pola atau model pendidikan yang sesuai dengan kebutuhan masyarakat setempat.

- Menyusun program pendidikan jangka pendek, menengah, dan panjang berdasarkan kebutuhan dan skala priotitas. 


\section{Model Pengembangan Pendidikan Wajib Belajar 12 Tahun di Kabupaten Bengkalis}

Sasaran diselenggarakannya Program Pendidikan Wajib Belajar 12 Tahun

Kabupaten Bengkalis adalah:

1. Meningkatkan akses dan perluasan kesempatan belajar bagi semua anak usia pendidikan menengah, dengan target utama daerah dan masyarakat miskin, terpencil, dan terisolasi.

2. Meningkatkan kualitas dan relevansi pendidikan menengah, sehingga setiap tamatan mempunyai kompetensi dasar yang dapat digunakan untuk hidup dalam masyarakat atau melanjutkan pendidikan ke jenjang yang lebih tinggi.

3. Meningkatkan efisiensi manajemen pendayagunaan sumberdaya pendidikan dan mengupayakan agar semua lembaga pendidikan dapat melaksanakan fungsinya secara lebih efisien dan efektif.

4. Meningkatkan akses pendidikan menengah harus dilakukan bersama-sama dengan perbaikan mutu pendidikan. Dengan demikian, pelaksanaan wajar 12 Tahun tidak dapat dipisahkan dengan upaya peningkatan mutu pendidikan.

Penyelenggaraan Wajib Belajar 12 Tahun artinya adalah meningkatkan akses dan perluasan kesempatan belajar bagi semua anak usia sekolah pendidikan menengah (16-18 tahun) untuk semua lapisan masyarakat sampai kepada pedesaan terpencil dan pedalaman, termasuk anak yang tidak melanjutkan pendidikan atau putus sekolah, serta anak yang mempunyai kelainan.

Oleh karena itu model penyelenggaraan Wajib Belajar ini terdiri atas jalur pendidikan formal yaitu SMA dan sederajat dan jalur pendidikan non-formal yaitu Paket C melalui kegiatan kelompok belajar yang setara dengan SLTA. Beberapa jenis satuan pendidikan di bawah ini dapat dijadikan sebagai pedoman bagi Pemerintah Kabupaten Bengkalis dalam rangka memilih model yang tepat sesuai dengan kebutuhan dan karakteristik wilayah dan penyebaran anak usia sekolah:

1. SMA Reguler, jalur formal dan jenis pendidikan umum dan penyelenggaraanya dapat dilaksanakan melalui beberapa alternatif antara lain pembangunan unit sekolah baru (USB) atau penambahan ruang kelas baru (RKB) atau pada daerah tertentu sepanjang jumlah guru mencukupi dan belum mencapai tugas mengajar optimal secara terbatas dapat dilaksanakan double shift.

2. SMA Terpadu, selain menerima calon siswa yang normal juga menerima calon siswa yang memiliki kelainan atau tuna tertentu. Sekolah ini memerlukan guru pembimbing khusus, yang dibantu dari SMALB atau SLB terdekat.

3. SMA Luar Biasa, SMA yang menampung calon siswa dari tamatan SLTP yang memiliki kelainan.

4. Sekolah Luar Biasa, sekolah luar biasa yang menampung calon siswa dari pendidikan dasar dan pendidikan menengah yang memiliki kelainan.

5. SMP-SMA Satu Atap, pengembangan SMA Reguler yang lokasinya menyatu atau berdekatan dengan SLTP pendukungnya yang terletak di daerah terpencil, terisolisasi, dan terpencar. 
6. SMK, jalur formal dan jenis pendidikan kejuruan/ketrampilan khusus.

7. Madarasah Aliyah (MA).

8. Pondok Pesantren.

9. Ujian Persamaan.

10. SMA Terbuka, sekolah yang menitik beratkan pada belajar mandiri dengan dilengkapi tatap muka secara terbatas, serta memiliki Kelompok Kegiatan Belajar (KKB) dan SMA Induk. Keduanya merupakan satu kesatuan yang tidak dapat dipisahkan. Bahan ajar utamanya adalah modul dan dilengkapi dengan media belajar yang sesuai. Lama pendidikan 3 tahun.

11. Kelompok Belajar Paket $C$, pendidikan jalur non-formal yang diselenggarakan dalam kelompok belajar dan memberikan program pendidikan setara dengan SLTA. Sasaranya adalah anak lulusan SLTP yang karena sesuatu hal tidak dapat melanjutkan ke SLTA reguler dan anak putus sekolah usia 16-18 tahun.

Berdasarkan data dan hasil analisis maka model pengembangan wajib belajar 12 tahun di Kabupaten bengkalis yang paling relevan berdasarkan prioritas adalah:

1. Pembangunan Unit Sekolah Baru berupa SMA/MA/SMK Reguler. Hal ini dapat dilakukan di Kecematan Bengkalis berupa SMA dan SMK Keputrian, Kecamatan Pinggir yaitu SMA, Kecamatan Rupat yaitu SMK Pertanian dan Perikanan, Kecamatan Rupat Utara berupa SMA/SMK, Kecamatan Rangsang berupa SMA/SMK Perikanan, Kecamatan Siak Kecil berupa SMA, Kecamatan Bagan Batu berupa SMA/SMK, Kecamatan Tebing Tinggi berupa SMK. Di samping pembangunan Unit Sekolah Baru dapat pula dilakukan penambahan lokal di Kecamatan Rangsang (SMAN 2) dan Kecamatan Tebing Tinggi (SMAN 1), Kecamatan Bantan (SMA Teluk Pambang).

2. Pelaksanaan Kegiatan Kelompok Belajar Paket C, dikarena hampir di semua Kecamatan terdapat anak yang putus sekolah atau tidak melanjutkan pendidikan ke SLTA maka Program ini dapat dilaksanakan pada setiap kecamatan.

3. Pelaksanaan Ujian Persamaan, khusus bagi masyarakat yang sudah bekerja tamat SMP atau putus sekolah pada SMA tetapi telah memiliki pekerjaan tetap, hal ini dapat dilaksanakan di Ibukota Kabupaten.

4. Pembangunan SMA Luar Biasa, dapat dilakukan di Kecamatan Bengkalis dengan membangun Unit Sekolah Baru atau satu atap dengan SMP LB yang ada.

5. Pembangunan SMA Terbuka, sekolah ini khusus untuk daerah/wilayah Kecamatan yang memiliki masyarakat marginal seperti di Kecamatan Bantan, Kecamatan Merbau, dan Kecamatan Rupat Utara.

\section{SIMPULAN}

1. Terdapat empat strategi pengembangan model wajib belajar 12 tahun, yaitu: a) Strategi dengan memanfaatkan seluruh kekuatan untuk merebut dan memanfaatkan peluang sebesar-besarnya (Strengths-Opportunities/SO), b) Strategi dengan menggunakan kekuatan yang dimiliki untuk mengatasi 
tantangan (Strengths-Treath/ST), c) Strategi berdasarkan pemanfaatan peluang yang ada dengan cara meminimalkan kelemahan yang ada (WeaknessesOpportunities/WO), dan d) Strategi yang didasarkan pada kegiatan yang berusaha meminimalkan kelemahan yang ada serta menghindari tantangan (Weaknesses-Treath/(WT).

2. Posisi pengembangan wajar 12 tahun Kabupaten Bengkalis pada Posisi Organisasi berada pada Kuadran III (tiga) dengan karakteristik sebagai berikut: a) Organisasi menghadapi peluang yang besar tetapi sumberdayanya lemah; b) Karena itu tidak dapat memanfaatkan peluang tersebut secara optimal, kecuali dapat meminimalkan kendala-kendala yang dihadapi; dan c) Fokus strategi organisasi pada posisi ini ialah mengatasi kelemahan-kelemahan atau meminimalkan kendala-kendala internal.

3. Model pengembangan Wajib Belajar 12 Tahun di Kabupaten Bengkalis adalah: (1) Pembangunan Unit Sekolah Baru berupa SMA/MA/SMK Reguler; (2) Pelaksanaan Kegiatan Kelompok Belajar Paket C; (3) Pelaksanaan Ujian Persamaan SMA; (4) Pembangunan SMA Luar Biasa; dan (5) Pembangunan SMA Terbuka.

\section{SARAN-SARAN}

1. Melakukan sosialisasi Wajar 12 tahun dalam rangka menumbuhkan partisipasi dan memberdayakan masyarakat termasuk lembaga keagamaan, organisasi sosial, dan Lembaga Swadaya Masyarakat (LSM) untuk mendukung, menyelengarakan, dan mengembangkan Program Pendidikan Wajib Belajar 12 Tahun dalam rangka meningkatkan pemahaman masyarakat mengenai pentingnya pendidikan bagi semua.

2. Menyediakan berbagai alternatif layanan pendidikan menengah sesuai dengan model pengembangan Wajar 12 tahun, baik formal (umum dan kejuruan) maupun non formal untuk memenuhi kebutuhan, kondisi, dan potensi anak termasuk anak dari keluarga miskin, keluarga marginal dan yang tinggal di wilayah pedesaan, terpencil, dan pedalaman.

3. Menyediakan sarana dan prasarana pendidikan termasuk pembangunan Unit Sekolah Baru SMA/MA/SMK, penambahan lokal/ruang kelas baru (RKB), laboratorium, perpustakaan, buku-buku pelajaran dan peralatan peraga/media pembelajaran, disertai dengan rehabilitasi dan revitalisasi sarana dan prasarana yang rusak.

4. Pengadaan tenaga guru SMA/SMK secara lebih merata, bermutu, tepat bidang studi, tepat lokasi, terutama untuk daerah pedesaan sesuai kebutuhan, dan peningkatan kualifikasi guru dari Diploma ke Strata Satu (S1) dan peningkatan kesejahteraannya.

5. Strategi dan model pengembangan wajib belajar 12 tahun di Kabupaten Bengkalis ini dapat diterapkan di daerah lain sepanjang daerah tersebut ada kesamaan karakteristik sosial ekonomi masyarakat dengan Kabupaten Bengkalis. 


\section{DAFTAR PUSTAKA}

Bappeda Kabupaten Bengkalis, 2002. Properda Kabupaten Bengkalis. Pemda Kabupaten Bengkalis. Bengkalis.

Bappeda Kabupaten Bengkalis, 2005. Laporan Tahunan Sosial Ekonomi Kabupaten Bengkalis. Pemda Kabupaten Bengkalis. Bengkalis.

Bappeda Kabupaten Bengkalis, 2005. Bengkalis Dalam Angka. Pemda Kabupaten Bengkalis. Bengkalis.

Bappeda Provinsi Riau, 2000. Properda Provinsi Riau. Pemda Propinsi Riau. Pekanbaru.

Bappeda Provinsi Riau, 2004. Master Plan Provinsi Riau. Pemda Propinsi Riau. Pekanbaru.

Balitbangda Kabupaten Bengkalis, 2007. Kajian Pengembangan Model Wajib Belajar 12 Tahun Di Kabupaten Bengkalis. Bengkalis.

BPS, 2007. Bengkalis Dalam Angka. BPS-Bappeda Kabupaten Bengkalis. Bengkalis.

Dinas Pendidikan Kabupaten Bengkalis, Laporan Kegiatan Tahun 2006. Bengkalis.

Dinas Pendidikan Provinsi Riau, 2001. Masterplan Percepatan Mutu Pendidikan Dasar dan Menengah Propinsi Riau. Dinas Pendidikan Propinsi Riau. Pekanbaru.

Dinas Pendidikan Provinsi Riau, 2003. Data Survei Pendidikan Dasar dan Menengah Propinsi Riau. Dinas Pendidikan Propinsi Riau. Pekanbaru.

Dinas Pendidikan Provinsi Riau, 2004. Data Survei Pendidikan Dasar dan Menengah Propinsi Riau. Dinas Pendidikan Provinsi Riau. Pekanbaru.

Dinas Pendidikan Provinsi Riau, 2004. Sensus Pendidikan Propinsi Riau. Dinas Pendidikan Propinsi Riau. Pekanbaru.

Dinas Pendidikan Provinsi Riau, 2007. Laporan Kegiatan Tahun 2007. Pekanbaru.

Diknas Republik Indonesia, 2002. Undang-undang Sisdiknas. Departemen Pendidikan Nasional. Depdiknas. Jakarta. 
Departemen Pendidikan Nasional, 2003. Baru 28 Persen Anak Usia Dini Memperoleh Layanan Pendidikan: //www.depdiknas.go.id/publikasi/Buletin/Padu/Perdana/padu 00.htm. Balitbang - Depdiknas. Diakses 25 Nov 2007.

Departemen Pendidikan Nasional, 2003. Perlu Gerakan Usia Din., http://www.depdiknas.go.id/publikasi/Buletin/Padu/Perdana/padu 00.htm. Balitbang - Depdiknas. Diakses 25 Nov 2007.

Departemen Pendidikan Nasional, 2003. Visi dan Misi Pendidikan Nasional http://www.depdiknas.go.id/publikasi/Buletin/Padu/Perdana/padu_00.htmBalitbang

- Depdiknas. Diakses 1 Desember 2007.

Hunger, J. David \& Wheelen, Thomas L. 2007. Strategic Management. AddisonWesley Publishing Compaby. Inc.

Juran, J.M. 2000. Kepemimpinan Bermutu. Pustaka Binaman Pressindo. Jakarta.

Kantor Wilayah BKKBN Provinsi Riau. Laporan Kegiatan Tahun 2006. Pekanbaru.

Pemerintah Daerah Kabupaten Bengkalis, Rencana Pembangunan Jangka Menengah Tahun 2006-2010.

Slamet, Margono, 1999. Pembelajaran Bermutu, Peningkatan Mutu Proses Pembelajaran dengan Pendekatan Manajemen Mutu Terpadu. Head ProjectDepdikbud. Jakarta.

Tjiptono, Fandy. 2007. Total Quality Manajeme., Andi. Yogyakarta. 